\title{
El virus del Ébola y la medicina respiratoria
}

\author{
Sergio Monraz-Pérez, * Patricia Volkow, ${ }^{*}$ Rogelio Pérez-Padilla* $\bowtie$ \\ *Instituto Nacional de Enfermedades Respiratorias Ismael Cosío Villegas, Ciudad de México; ‘nstituto Nacional de Cancerología. \\ Trabajo recibido: 10-X-2014; aceptado: 17-X-2014
}

El brote más grande hasta ahora conocido por el virus de Ébola, inició en diciembre 2013, en la nación de Guinea-Conakry al oeste de África, de ahí se diseminó a los vecinos países de Liberia, Sierra Leona y Nigeria. No fue hasta marzo del 2014 que el brote fue confirmado por la ONU y en agosto 2014 se declaró como una Emergencia Pública Sanitaria Internacional, ${ }^{1,2}$ cuando el número de víctimas se contaban por centenas. Las recientes publicaciones testimoniales de extranjeros trabajando en los países afectados por el Ébola ofrecen dramáticas imágenes que pareciesen mostrar que se está perdiendo la batalla contra el Ébola. Los gérmenes, ahora el Ébola, desconocen los arbitrarios límites geográficos, ${ }^{3}$ como lo hizo el virus de la inmunodeficiencia humana en los ochenta y el de la influenza AH1N1 en el 2009. Hasta septiembre 23 del 2014, la OMS ha reportado 6574 casos confirmados de Ébola en Guinea, Liberia, Nigeria, Senegal y Sierra Leona con 3091 muertes. ${ }^{4}$

Los rápidos medios de transporte permiten ahora que millones de seres humanos se desplacen por el planeta en forma casi instantánea, de lugares remotos a ciudades densamente pobladas, donde sus habitantes viven hacinados, muchos de ellos migrantes del campo o de otras regiones generando exposiciones insospechadas. En Dallas, Texas, recién murió un enfermo de Ébola que desarrolló los síntomas de la enfermedad cinco días después de su llegada, mismos que fueron menospreciados por el sistema de salud a pesar de que la epidemia está en todos los diarios. ${ }^{5}$ Los movimientos humanos se suman a una pobre y debilitada infraestructura en salud pública, con niveles bajos de educación y sanidad, y recursos limitados para prevención y manejo de enfermedades, para hacer difícil y a veces imposible el control de brotes.

El virus de Ébola y el virus de Marburg son filovirus (virus filamentosos), de ARN, con cinco especies al menos y ocasiona la fiebre hemorrágica de Ébola pa- recida al choque séptico fulminante ${ }^{1}$ con una letalidad de al menos el $50 \%$ pero que ha llegado al $88 \%$. $^{.} \mathrm{Se}$ transmite tras el contacto con animales infectados, o con fluidos de enfermos, sangre, vómito, orina, heces y probablemente el sudor ${ }^{6}$ pero, afortunadamente, no por cercanía o contacto casual con enfermos sin el uso de equipo de protección adecuado, incluyendo un saludo de manos. ${ }^{7}$ Los trabajadores de la salud tienen riesgo máximo cuando atienden, sin protección adecuada a pacientes con Ébola no diagnosticado y han sido víctimas del brote.

Experimentos en animales de laboratorio han demostrado que los filovirus pueden iniciar la infección vía diferentes rutas incluyendo la ingestión, la inhalación y la vía transdérmica. ${ }^{6}$ Algunos contagios en humanos también pudieran deberse al inóculo de pequeñas cantidades de virus en la boca u ojos con las propias manos contaminadas con el virus, ${ }^{8,9}$ vía bien conocida para la influenza y otras infecciones. Los filovirus pueden ser transmitidos por aerosoles durante procedimientos médicos, sobre todo en pacientes con enfermedad muy avanzada. Raramente, según estudios epidemiológicos, ocurre la transmisión de persona a persona a través de la vía respiratoria. ${ }^{10}$ En el brote ocurrido en 1979 en Sudán, de 34 pacientes confirmados con Ébola en cinco familias, se observó que el contacto directo con el paciente y su cuidado sin tener medidas de protección ocasiona un riesgo 5.1 veces más de adquirir la enfermedad. Los que entraron al mismo cuarto sin estar en contacto con el paciente no presentaron la enfermedad. Este estudio de transmisión del virus entre los miembros de una familia demostró que el virus del Ébola es difícilmente transmitido vía aérea. ${ }^{11}$

El brote en Mayibou, Gabón, en 1996 ocurrió después de que 19 personas se comieron un chimpancé muerto y adquirieron la enfermedad. ${ }^{12}$ Otra vía posible de adquirir la enfermedad es por las secreciones y excretas de murciélagos, lo cual se ha reportado para el virus 
Marburg..$^{13}$ Se han documentado brotes hospitalarios iatrogénicos de Ébola con la reutilización de jeringas para la administración de medicamentos contra la malaria ${ }^{14} \mathrm{o}$ en cirugías por inhalación de aerosoles. ${ }^{15}$

Cualquiera que sea la vía de entrada en el cuerpo, los macrófagos y las células dendríticas suelen ser las primeras células en ser infectadas, con diseminación de los filovirus replicados a ganglios linfáticos locales, y posteriormente a hígado, bazo, timo y otros tejidos linfoides. ${ }^{16,17}$ Tras una incubación de 8-10 días, aparecen síntomas tipo influenza (tabla 1): cefalea, mialgias, inicio abrupto de fiebre, escalofríos, malestar general, debilidad generalizada, anorexia y dolor torácico. ${ }^{18}$ Puede haber tos no productiva y odinofagia. Algunos días después aparecen náusea, vómito, diarrea, dolor abdominal y puede aparecer un exantema maculopapular. En los casos más graves se observan hemorragias en diversos sitios, desde petequias, equimosis y sangrado de mucosas del tubo digestivo que pueden ser masivas, falleciendo hasta el $90 \%$ de los pacientes con el cuadro clínico que incluye deshidratación, choque, acidosis láctica, falla renal aguda, daño hepático y falla orgánica múltiple.

En el SIRA por Ébola, como en el causado por otros agentes se han implicado la liberación de interleucinas y citosinas, iL-1, iL-6, iL-8, iL-10 (antiinflamatoria), iL-12, TNF, IFN $\gamma$, con quimiotaxis y activación de monocitos, neutrófilos y linfocitos, activación del complemento, generando inflamación, extravasación de líquidos y necrosis. ${ }^{18}$ En un brote previo se analizaron 103 pacientes, 84 fallecidos; de los cuales, el 56\% presentó odinofagia, $31 \%$ taquipnea, $10 \%$ dolor torácico, $7 \%$ tos, $3 \%$ epistaxis y $2 \%$ hemoptisis. ${ }^{19}$ En otro estudio de las manifestaciones clínicas ocurridas durante un brote en una población en Bundibugyo, Uganda, en noviembre 2007-febrero 2008 ocurrió dolor torácico (en $27 \%$ de los pacientes), disnea (19\%), tos (15\%), epistaxis ( $8 \%$ ) y hemoptisis (4\%). ${ }^{20}$ Los principales hallazgos de laboratorio son: leucopenia, linfopenia, trombocitopenia, elevación de transaminasas, alteraciones renales y prolongación del TP y TPT con productos de degradación de la fibrina (CID, en casos graves), elevación de amilasa. ${ }^{21}$ En fases tardías puede haber leucocitosis.

Tabla 1. Manifestaciones respiratorias del Ébola.

Síndrome gripal semejante a influenza al inicio

Odinofagia (56\%)

Taquipnea (31\%)

Dolor torácico (10\%)

Tos (7\%)

Hemoptisis (2\%)

SIRA y falla orgánica múltiple
Los sobrevivientes suelen mejorar entre los días 6 a 11 después de la aparición de los síntomas con resolución de la viremia y la aparición de anticuerpos específicos para el virus, ${ }^{22}$ pero con una convalecencia prolongada y caracterizada por debilidad, fatiga, y dificultad para subir de peso. ${ }^{23}$ En casos fatales, ocurren signos de manera temprana y más severa, incluyendo taquipnea con falla renal, progresión a falla orgánica múltiple y choque séptico. La muerte ocurre entre los días 6 y 16.

Fuera de los brotes, es difícil sospechar el diagnóstico, pero en estos momentos es obligado considerarlo en pacientes enfermos con viaje reciente a África, aun cuando no recuerde el contacto con animales o posibles enfermos especialmente en personal relacionado a la salud o investigadores relacionados con el Ébola. También en personas que tuvieron contacto con enfermos o con chimpancés o gorilas enfermos, visitas a cuevas donde habitan murciélagos. Los diagnósticos diferenciales pueden consultarse en la tabla 2.

En ausencia de tratamiento específico, el manejo será de soporte y éste puede reducir considerablemente la alta tasa de mortalidad reportada en África, donde la infraestructura hospitalaria, el personal de salud y los insumos médicos son extremadamente escasos para atender enfermos graves.

Ante la sospecha de que existe la transmisión aérea del virus de Ébola es indispensable extremar precauciones con todos los procedimientos respiratorios que generan aerosoles. Las recomendaciones de la CDC para procedimientos generadores de aerosoles (intubación y extubación orotraqueal, broncoscopias, inducción de esputo, aspiración de secreciones con técnica abierta, ventilación con presión positiva), son: realizar el procedimiento en área de aislamiento, limitar el número de personal durante el procedimiento, uso

Tabla 2. Diagnóstico diferencial.

Malaria
Tifoidea
Fiebre amarilla
Fiebre de Lassa
Varicela
Rubéola
Dengue
Influenza
Sepsis por bacterias Gram negativas
Síndrome de choque tóxico
Meningococcemia
Leptospirosis
* Considerar los sitios de viaje recientes y las condiciones epide-
miológicas.


como mínimo de cubrebocas N95 de alta eficiencia, así como las demás medidas de prevención (lavado de manos, uso de traje especial, desinfección con hipoclorito, manejo de residuos). ${ }^{24}$ Los recursos deben concentrarse en medidas de aislamiento, desinfección, adecuado manejo de residuos y fluidos corporales, más que en sistemas caros y complejos para la filtración de partículas aéreas, ya que el virus difícilmente es transmitido vía aérea.11

El traje utilizado al entrar en contacto con pacientes con enfermedad por virus de Ébola es de un material de plástico impermeable a secreciones y cubre cabeza, tronco y extremidades, además de guantes delgados y gruesos (doble guante), botas, cubrebocas, anteojos. Este equipo es más sofisticado y estricto que el utilizado habitualmente para prevenir influenza y el material debe desinfectarse después de su uso. Existen una serie de recomendaciones de la CDC para el control de la infección respecto al tipo de desinfectantes que deben utilizarse en hospitales, pero el hipoclorito de fácil acceso es primordial. ${ }^{25}$ Estas precauciones extremas se deben continuar con el manejo de cadáveres (preparación, transporte, desinfección de sitios en contacto). Se encuentran en proceso de investigación y fase experimental algunas vacunas contra esta enfermedad, que probablemente se prueben hasta 2015 y se espera una efectividad limitada. ${ }^{26}$

\section{CONCLUSIONES}

Es importante estar preparados para posibles casos importados de Ébola, que serían atendidos en principio en unidades de terapia intensiva generales por su gravedad, pero por la presencia de la falla orgánica múltiple que incluye la respiratoria, podrían presentarse también a unidades respiratorias sobre todo si se sobrepone con algún brote de influenza como ha ocurrido con el dengue en México. No debemos olvidar en la historia clínica los antecedentes laborales, los viajes recientes, los vuelos a zonas endémicas y la convivencia con personas con esta enfermedad e insistir en el aislamiento de los sospechosos y del aviso a las autoridades sanitarias. Todos los hospitales requieren áreas para el aislamiento de pacientes y control de las infecciones.

No olvidemos tampoco que los retos de salud mundial sólo se pueden enfrentar de manera eficaz con la colaboración internacional.

\section{REFERENCIAS}

1. World Health Organization. Global Alert and Response. Ebola virus disease. Accesed on August 22, 2014. Available from: http://www.who.int/csr/disease/ebola/en/.
2. Baize S, Pannetier D, Oestereich L, et al. Emergence of Zaire Ebola virus disease in Guinea. N Engl J Med 2014;371(15):1418-1425. doi: 10.1056/NEJMoa1404505.

3. Koplan J, Del Rio C. Global Health Beyond Ebola. The Atlanta Journal-Constitution. August 2014.

4. CDC. 2014. Ebola outbreak in West Africa. Atlanta, GA: US Department of Health and Human Services, CDC; 2014. Accesed on September 24, 2014. Available from: http:// www.cdc.gov/vhf/ebola/outbreaks/guinea/index.html

5. CDC. 2014. First imported case of Ebola diagnosed in the United States. Atlanta, GA: US Department of Health and Human Services, CDC; 2014. Accesed on October 1st, 2014. Available from: http://www.cdc.gov/vhf/ebola/outbreaks/2014-west-africa/united-states-importedcase.html

6. Mahanty S, Bray M. Pathogenesis of filoviral haemorrhagic fevers. Lancet Infect Dis 2004;4(8):487-498.

7. Centers for Disease Control and Prevention. Case definition for Ebola Virus Disease (EVD). Accessed on August 11, 2014. Available from: http://www.cdc.gov/vhf/ebola/ hcp/case-definition.html

8. Jaax NK, Davis KJ, Geisbert TJ, et al. Lethal experimental infection of rhesus monkeys with Ebola-Zaire (Mayinga) virus by the oral and conjunctival route of exposure. Arch Pathol Lab Med 1996;120(2):140-155.

9. Schou S, Hansen AK. Marburg and Ebola virus infections in laboratory non-human primates: a literature review. Comp Med 2000;50(2):108-123.

10. World Health Organization. Barriers to rapid containment of the Ebola outbreak. Accessed on August 12, 2014. Available from: http://www.who.int/csr/disease/ ebola/overview-august-2014/en/

11. Baron RC, McCormick JB, Zubeir OA. Ebola virus disease in southern Sudan: hospital dissemination and intrafamilial spread. Bull World Health Organ 1983;61(6):9971003.

12. Georges-Courbot MC, Sanchez A, Lu CY, et al. Isolation and phylogenetic characterization of Ebola viruses causing different outbreaks in Gabon. Emerg Infect Dis 1997;3(1):59-62.

13. Nakazibwe C. Marburg fever outbreak leads scientists to suspected disease reservoir. Bull World Health Organ 2007;85(9):654-656.

14. Piot P, Breman JG, Heymann DL, et al. Clinical aspects of Ebola virus infection in Yambuku area, Zaire, 1976. In: Pattyn S, editor. Ebola virus haemorrhagic fever. Amsterdam: Elsevier/North-Holland; 1978. p.17.

15. Khan AS, Tshioko FK, Heymann DL, et al. The reemergence of Ebola hemorrhagic fever, Democratic Republic of the Congo, 1995. Commission de Lutte contre les Epidémies à Kikwit. J Infect Dis 1999;179 Suppl 1:S76S86.

16. Mahanty S, Bray M. Pathogenesis of filoviral haemorrhagic fevers. Lancet Infect Dis 2004;4(8):487-498.

17. Bray M, Geisbert TW. Ebola virus: the role of macrophages and dendritic cells in the pathogenesis of Ebola hemorrhagic fever. Int J Biochem Cell Biol 2005; 37(8):1560-1566. 
18. Kobinger GP, Leung A, Neufeld J, et al. Replication, pathogenicity, shedding, and transmission of Zaire ebola virus in pigs. J Infect Dis 2011;204(2):200-208. doi: 10.1093/infdis/jir077.

19. Bwaka MA, Bonnet MJ, Calain P, et al. Ebola hemorrhagic fever in Kikwit, Democratic Republic of the Congo: clinical observations in 103 patients. J Infect Dis 1999;179 Suppl 1:S1-S7

20. Roody P, Howard N, Van Kerkhove MD, et al. ClinicalmManifestations and case managment of Ebola haemorrhagic fever caused by a newly identified virus strain, Bundibugyo, Uganda, 2007-2008. PLoS One 2012;7(12): e52986.doi:10.1371/journal.pone.0052986.

21. Kortepeter MG, Bausch DG, Bray M. Basic clinical and laboratory features of filoviral hemorrhagic fever. J Infect Dis 2011;204 Suppl 3:S810-S816. doi: 10.1093/ infdis/jir299.

22. Sanchez A, Lukwiya M, Bausch D, et al. Analysis of human peripheral blood samples from fatal and nonfatal cases of Ebola (Sudan) haemorrhagic fever: celular responses, virus load, and nitric oxid levels. J Virol 2004;78(19):10370-10377.

23. Rowe AK, Bertolli J, Khan AS, et al. Clinical, virologic, and immunologic follow-up of convalescent Ebola hemorrhagic fever patients and their household contacts, Kikwit Democratic Republic of the Congo. Commission de Lutte contre les Epidémies à Kikwit. J Infect Dis 1999;179 Suppl 1:S28-S35.
24. Centers for Disease Control and Prevention. Infection Prevention and Control Recommendations for Hospitalized Patients with Known or Suspected Ebola Virus Disease in U.S. Hospitals. Atlanta, GA: US Department of Health and Human Services, CDC; 2014. Accesed on September 24, 2014. Available from: http://www.cdc. gov/vhf/ebola/hcp/infection-prevention-and-controlrecommendations.html

25. Centers for Disease Control and Prevention. Interim Guidance for Environmental Infection Control in Hospitals for Ebola Virus. Atlanta, GA: US Department of Health and Human Services, CDC; 2014. Accesed on September 24, 2014. Available from: http://www.cdc.gov/vhf/ebola/ hcp/environmental-infection-control-in-hospitals.html

26. Kanapathipillai $R$, Restrepo AM, Fast P. Ebola vaccine - An Urgent International Priority. N Engl J Med 2014. doi: 10.1056/NEJMp1412166

\section{$\triangle$ Correspondencia:}

Dr. Rogelio Pérez Padilla, Clínica de Sueño, Instituto Nacional de Enfermedades Respiratorias Ismael Cosío Villegas. Calzada de Tlalpan 4502 , Col. Sección XV, 14080, México, D.F. Correo electrónico: perezpad@gmail.com

Los autores declaran no tener conflicto de intereses 